\title{
La curiosa quietud del paradigma: aprendizajes nómades en contextos de complejidad
}

\section{María Teresa Pozzoli*}

\begin{abstract}
Resumen: El viaje ha tenido un papel fundamental en la azarosa supervivencia humana, sin embargo nuestro paradigma es rico en quietudes y pautas fijas. De pronto, los escenarios se trastocan, sobreviene la crisis y nada será como era entonces. Todos estamos en tránsito, de conocimientos, de aprendizajes, de identidades, todos estamos forzados a ser migrantes, aunque la cabeza y el corazón intenten apegarse a una concepción del mundo y de la vida que pertenece a otra época ya pasada. El tercer milenio le ha dado buenas razones de emergencia a una comunidad trashumante cuyo origen es la misma inestabilidad a la que tenemos que enfrentarnos. Ese flujo es el cambio de paradigma. El Yo haciéndose es un Yo siempre en tránsito hacia otra parte. Pero para generar este paisaje quieto el sistema dispone de una serie de controles. Nuestra cultura 'reacciona' negativamente, desconfía del nomadismo, como también del extranjero. El desorden es una noción compleja, como lo es el encuentro entre muchos azares, que son generadores del caos.

Palabras clave: Sujeto Complejo, desorden, movimiento, nomadismo, caos
\end{abstract}

\section{The strange stillness of paradigm: nomads learnings in contexts of complexity}

\begin{abstract}
The journey has had a substantial role in the random human survival, yet our paradigm is rich in quietness and fixed patterns. Suddenly, the scenarios become confusing, crisis occurs and nothing will be as it used to be. We are all in transit, of knowledges, learnings, identities, we are all forced to become migrants, although the head and the heart try to adhere to a conception of world and of life that belongs to another bygone era. The third millennium has given good reasons to emerge, to a nomadic community whose origin is the same instability which we must face. That flow is paradigm shift. The Ego which is rising is an Ego always in transit to elsewhere. But to generate this landscape of stillness the system has a series of control mecanisms. Our culture 'reacts' negatively, distrusts nomadism, as well as strangers. Disorder is a complex notion, as is the encounter of many hazards, which generate chaos.
\end{abstract}

Keywords: Complex Subject, disorder, motion, nomadism, chaos

\footnotetext{
* Instituto de Pensamiento Complejo, Santiago, Chile.

Email: mariateresa.pozzoli@gmail.com
} 


\section{A curioso quietude do paradigma: aprendizagem nômades em contextos complexos}

Resumo: A viagem foi fundamental para a sobrevivência humana aleatório, mas o nosso paradigma é rico em sossego e padrões fixos. De repente, você ajustar os cenários, a crise ocorre e nada é como era então. Estamos todos no trânsito, de conhecimento, de aprendizagem, identidades, todos nós somos forçados a tornaremse migrantes, embora a cabeça eo coração tenta aderir a uma visão de mundo e da vida que pertence a outra era passada. O terceiro milênio tem dado bons motivos para uma emergência para uma comunidade nómada provenientes da mesma instabilidade que temos de enfrentar. Esse fluxo é a mudança de paradigma. $\mathrm{O}$ Eu se-fase cada vez eu em trânsito para outra parte. Mas para gerar esta paisagem ainda o sistema tem uma série de verificações. Nossa cultura "reagir" de forma negativa, tem cuidado com o nomadismo, bem como no estrangeiro. O distúrbio é uma noção complexa, como é o encontro de muitos riscos, que geram o caos.

Palavras-chave: assunto complexo, a desordem, o movimento, o nomadismo, chaos

Recibido: 30.01.2010

Aceptado: 25.02.0210

$* * *$

El caos es una forma de organización que contradice otras formas de organización, el caos es contradicción, movimiento, una sociedad que se vuelve estática se condena a desaparecer. Es preciso estimular la diferencia, la contradicción y la imaginación para genera nuevos

paradigmas.

La realidad social nos muestra cada vez con más insistencia y en realidades muy diversas que todos formamos parte -activa o pasivamentede un horizonte actual de movilidad y migración; un tránsito que se hace cada vez más extensivo a diferentes dominios que se van acoplando en una sola trama de complejidad. Sea, como trashumancia, diáspora, errancia, exilio o nomadismo, o simplemente, o por el hecho de tener que asumir que una parte de nuestro ser se siente un poco extranjera aunque permanezca en su lugar de origen.

El espacio del nuevo nomadismo no es el territorio geográfico ni el de las instituciones o de los Estados, sino un espacio invisible de conocimientos, de saber, de potencias de pensamiento en cuyo seno nacen y se transforman cualidades de ser, maneras de actuar en sociedad.

La mejor cara de los cambios generados por la globalización, nos dice de estos factores móviles, que se acompañan de desórdenes y de perplejidades; me refiero a lo que sigue generando el sorprendente avance tecnológico que ha modificado los parámetros del concepto del espacio, y la connotación súbitam instantánea que tiene el tiempo por la aceleración que esa tecnología nos permite. Muchos fenómenos que se multiplican en 
este mundo globalizado tienen que ver con el movimiento, aunque otras tragedias hablen de estancamiento, de fijación y de indiferencia. La vida de una considerable porción de la humanidad está fijada a condiciones de subexistencia y de indignidad. Muchos de ellos, queriendo huir de tales condicionamientos, forzosamente, tienen que moverse de sus lugares de origen para intentar esquivar el daño que genera este sistema productor de bienes que también produce hambre, patologías sociales, concentración de la riqueza y la dilapidación de recursos naturales no renovables. En este escenario ocurre la emergencia de una comunidad trashumante, en la que todos, sin saberlo estamos incluidos.

En algún sentido, todos estamos en tránsito, en tránsito de conocimientos, de aprendizajes, de identidades, todos somos, o estamos forzados a ser migrantes, aunque la cabeza y el corazón intenten apegarse a una concepción del mundo y de la vida que pertenece a otra época ya pasada. El tercer milenio le ha dado buenas razones de emergencia a una comunidad trashumante cuyo origen es la misma inestabilidad a la que tenemos que enfrentarnos.

Los seres humanos si bien somos atávicos y necesitamos de condiciones de regularidad para desarrollarnos, también leemos las oportunidades que se nos hacen presentes y nos permiten descubrirnos como 'máquinas vivas', sobrepasando las aparentes limitaciones de nuestra estructura. Capaces de poner en acción múltiples capacidades y cualidades hasta ese momento desconocidas para hacer frente a los incesantes cambios de las circunstancias de la vida. El desmantelamiento del trabajo "fijo", la imposición de modelos económicos y de vida excluyentes, el cambio climático y la alteración de los ciclos de la naturaleza, las hambrunas, las guerras por conflictos religiosos, raciales y políticos, las catástrofes ambientales, persecuciones, invasiones y despojos territoriales, ponen a prueba la estabilidad emocional y la capacidad de aprendizaje. De pronto, los escenarios se trastocan, sobreviene la crisis de condiciones antes estables y ya nada será como era entonces...o nada volverá a ser como quisimos en otro momento que fuera.

\section{El "Yo haciéndose"}

Los mitos nos han hablado muchas veces de un Yo que se enfrenta a un Tú, confrontación que es esencial a esa concepción binaria y fija, polar y estática, inercial, que distingue al paradigma que reproducimos aunque lo sabemos y afirmamos la necesidad de cambiarlo. El discurso no es coherente con la acción.

La resistencia del paradigma, de las instituciones, tienen que ver con nuestras elecciones cotidianas, y dicen de la dificultad para dar cuenta de la complejidad del mundo. Sólo seguimos viendo el Yo y el Tú, en un camino que es el de la inexorable autodestrucción, en tanto no podamos traducir ese Yo y ese Tú, -mutuamente excluyentes- en un Él impersonal, 
en el que la dupla de oposición están contenidos y representados. El "Él” opera bajo la forma de la terceridad simbólica, no sólo a nivel lingüístico sino también institucional. Sin el "Él” sólo quedaríamos fijados al mero juego especular, tan presente en las mitologías universales. Existe un comportamiento casi ancestral en el que el Yo ${ }^{1}$ también es el Tú, (el Otro) y viceversa, y sin darnos cuenta, esa fijeza, nos ha incentivado al ejercicio de una violencia y de una agresividad absolutamente innecesarias y paradojales, al atacar una parte de nosotros mismos y a toda la comunidad, comprometiendo incluso a nuestros descendientes por aquello que llamamos "memoria”, o "la venganza del crimen originario” (Girard, 1998).

En cuanto a la sociabilidad, más específicamente, el surgimiento de la comunidad trashumante como fenómeno contemporáneo asociado con el tema de las diferencias ${ }^{2}$, vuelve indispensable una ética, una cultura de la hospitalidad $^{3}$ que la acompañe, una lucha profunda con nosotros mismos para desterrar el miedo, la ira, para abrir nuestras puertas (Lévinas: 2006, 190).

En hebreo, hay dos maneras de decir "Yo": Anokhi y Ani. Anokhi, tendría el significado de un"Yo" ya realizado, acabado y definitivo, y Ani significa el "Yo haciéndose", en movimiento (Ouaknin, 1994). Al estar fijados en la lógica de poder binaria, limitamos la expresión del "Yo haciéndose”, dando aire a la fantasía de que somos Anokhi. El Yo haciéndose es un Yo siempre en tránsito hacia otra parte.

\section{Errancia y Mitología}

El primer ser errante fue Caín, que al matar a su hermano Abel, reflejó para siempre la condición de ser un hombre castigado por Dios, maldito, desterrado. Condenado a vagar por siempre y convirtiendo en polvo estéril la tierra que pisaba. "Errante y vagabundo vivirás por el mundo” afirma en tono de profecía irrevocable el Génesis del Antiguo Testa-

\footnotetext{
${ }^{1}$ Santiago Kovladoff señala que en estos dos significantes para nombrar al Yo - Ani y Anokhi - hay una diferenciación lingüística que da cuenta de los dos modos de articulación del YO-TÚ, a saber el narcisístico-especular (anokhi); y el simbólico (ani).

${ }^{2}$ Los musulmanes consideran que la diferencia es tan importante como la existencia de la contradicción -tanto para el desarrollo de las personas como en la sociedad-. Un mundo sin diferencias está condenado a desaparecer. Igual que lo estático tiende a anularse por no ser dinámico la uniformidad social es la antesala del cambio que supera o anula lo existente. Todo lo que se detiene o se inmoviliza tiende a dañarse o corromperse.

${ }^{3}$ Ética hospitalaria que obliga y doblega la tradición del rechazo y que erige una política, una justicia para millones de "sin papeles" y de "sin domicilio", donde emerge otro derecho internacional, otra política de fronteras, una política de lo humanitario, para acceder a las “ciudades hospitalarias”. Cosmopolitas del mundo, un esfuerzo más” (Derridá), para acoger, para recibir al neo-errante, al "socioasteroide” (Virilio, idem), para dar derechos a los "sin derechos".
} 
mento y, “...caminarás sobre la tierra, la que se negará incluso a acogerte como muerto”. Extraña soledad, aguda melancolía de la existencia, que el imaginario de la mitología asocian al destino de estos seres.

Al Holandés Errante se le atribuyen significaciones similares por haber cometido otro crimen horrendo. Condenado a vagar por los océanos sólo podía desembarcar cada siete años para abastecer de víveres a su tripulación fantasma. La única salida a este infierno sería tomar contacto con el amor de una mujer que pudiera redimirlo. Mientras tanto, no podría eludir el peso de la pena eterna que lo haría pagar las culpas siendo vigilado por el ojo evaluador de una autoridad que no perdona. Sin embargo, este impasse no es sólo un rasgo de la cultura judeocristiana... la figura del errante está presente en la filosofía budista, como el que transita libre por la vida; y en la mitología griega se asocia a Ulises como el personaje que encarna al viajero perenne, y en los trayectos seguidos por Prometeo, Tántalo, Ixión y Sísifo el oprobio humillante de caminar para no llegar nunca a su destino

La errancia aparece en nuestras culturas aparece como castigo, como un síntoma de lo (des)originado, -no sólo en cuanto a estar fuera del origen de los parámetros que estatuyen los colectivos- sino también por hallarse en una búsqueda que no cesa, en cuanto a la certeza de su origen, y al sentido último de su originalidad. También errancia significa (des)finalizado, ya que el destino de lo humano en el planeta se mantiene titubeante, incierto, lleno de amenazas e inhibido de oportunidades, lo que cuestiona la idea misma de su finalidad y de su porvenir. El destino ha de ser hallado en 'otra parte’. Así, los parámetros fijados por nuestro paradigma a-normalizan la errancia, al tiempo que opta, unidimensionalmente, por la bondad de lo fijo, de lo inmóvil, de lo estático, de lo sedentario y poseído, de lo quieto como disciplinado y previsible. Lo quieto está quieto, por dos posibles razones, porque está enfermo o está muerto, para el Pensamiento Complejo, lo vivo se mueve. Y para generar este paisaje quieto el sistema dispone de una serie de controles, tan eficientes como lo fueron aquellas mitologías a lo largo de los siglos, como las leyendas de Caín o del Holandés Errante.

Siempre hay un personaje presentado como el enemigo del orden social. En Norteamérica se desarrolla el imaginario de un indio enemigo, violento y perturbador. Este personaje se cambia por el comunista ateo, ahora tratan de imponer la idea del musulmán despiadado, machista, fundamentalista y terrorista. El fondo de estas creaciones encierra el propósito de ocultar la verdad; el motor de estas creaciones son los intereses particulares de quienes crean el imaginario. Simples personajes desmistificables, aislados, sin embargo, presentes en la sociedad de manera intermitente generando un mínimo de caos.

No solamente por etnocentrismo, o patriotismo primitivo, nuestra cultura “reacciona” negativamente, desconfía del nomadismo, como también del extranjero. Con ellos... las mayorías sufren un desorden. Pero, el 
desorden aquí lo entendemos como una noción compleja, como el encuentro entre muchos azares, como series causales deterministas de orden diferente, consideradas generadoras del caos-(Morín, 1984).

En esos personajes, no se encuentran los referentes de las mismas tradiciones dominantes, no permiten orientarse por la pertenencia a la misma tierra que el observador usa como referente y está fijado, como tampoco exhibe un apellido del que se desprenda la historia familiar, ni puedan preverse sus costumbres que indican pertenencias sociales, económicas, culturales o padrinazgos. Frente al bárbaro hay un inevitable tema de desconfianza.

\section{El modo trashumante y la naturaleza}

Un texto sencillo y sentido de Alejandro Abufón, que hallé en mi biblioteca habla de "El modo transeúnte" (o trashumante, o nómade, agrego) que describe como una actitud interior que no permite quedarse (fijado) en un estado interior, ¿ 0 anterior?, lo que significa revalorizar el estar en tránsito como opción de vida, pero aún más, como ‘sentido’ (existencial) o como manera sabia de enfrentar la vida. Y en este aspecto también hay un tema de paradigma, dado que el modo transeúnte conlleva una movilidad esencial que se gana, o a la que se accede, una vez que se alcanza cierto nivel superior de desarrollo psico-socio-cognitivo-espiritual. Desarrollo integral que difícilmente alcanzamos con la educación formal y familiar, pues por lo menos para los citadinos, nos educan al margen de la interpretación de los signos de la naturaleza.

Entre las aves, por ejemplo, existen diversas especies que tienen hábitos migratorios, que saben utilizar un misterioso instrumental de vuelo asociado con los signos de la naturaleza. Esta referencia les permite sobrevivir a la incertidumbre que despierta el inicio de cualquier viaje.

En este mismo sentido, Kevin Kelly (1994) en su obra "Fuera de control: el surgimiento de una civilización neobiológica” apuesta a que si fuéramos conscientes de las limitaciones del paradigma 'quieto' que venimos reproduciendo- podríamos ser capaces de emular los sistemas de complejidad magistral implicaos en la vida de la naturaleza ${ }^{4}$. Pero, para ello debieramos acordar como punto de partida el desprecio de toda rígida concepción, cerrada al cambio y la innovación, que pudiera entender la inmodificabilidad de un supuesto plan maestro, algo 'dado', que no puede ser puesto en duda, así como es presentado como dogma religioso. Kelly, propone prestar atención a algunos principios extraídos de la sabiduría de la naturaleza, a saber:

\footnotetext{
${ }^{4}$ La mayoría de los procesos naturales están gobernados por el azar y la autoorganización, por la aleatoriedad y la autonomía, por procesos de inestabilidad.
} 
- Los sistemas naturales distribuyen la inteligencia hacia el exterior y rechazan la autoridad centralizada. Ellos se controlan de abajo hacia arriba.

- Los sistemas naturales logran la complejidad mediante la creación de múltiples capas de simplicidad. Ellos crecen por partes.

- Los sistemas naturales sobreviven gracias al impulso de la diversidad, la excentricidad, y la inestabilidad. Ellos maximizan sus límites.

- Los sistemas naturales, aún en los conocidos como sistemas estables, persiste la búsqueda del desequilibrio. Ellos no buscan el manejo del cambio, sino que lo impulsan.

- Los sistemas naturales no solo cambian, ellos cambian de acuerdo al cambio. Ellos se organizan en torno a reglas de autotransformación.

Los de la naturaleza son códigos flexibles que se oponen a la lógica de nuestro paradigma tan rico en quietudes y pautas fijas, que de no hacer nuevos aprendizajes podrían acompañar nuestra auto-extinción, por no poder ser capaces de reencontrar el camino del viaje.

Un viaje que no ha de ser "huida", sino búsqueda incesante, tan ancestral en sus motivos que pareciera que permite recuperar una especie de bitácora ontológica, dadas las incidencias que ha tenido el viaje en la azarosa supervivencia humana. El viaje de la vida, su secuencia es una metáfora del tránsito que cada uno realiza en un sentido psicológico profundo (arquetipal), es el Camino del Héroe, un héroe como todo individuo consciente que a lo largo de su vida camina en la dirección de su realización personal.

\section{El nomadismo en la tecnología}

Moverse, ya no es desplazarse de un punto a otro de la superficie terrestre, sino atravesar universos de problemas, de los mundos vividos, de paisajes de sentido como derivas por las texturas de humanidad. Las navegaciones transversales, heterogéneas de los nuevos nómadas exploran nuevos e impensados espacios. Afirma Maffesoli que "somos inmigrantes del subjetivismo". El nomadismo de este tiempo tiene que ver ante todo con la transformación continua y rápida de los paisajes científicos, técnicos, profesionales y mentales. Incluso si no nos moviésemos, el mundo seguiría cambiando alrededor nuestro. Sin embargo, la tendencia es que finalmente nos movemos. Y el conjunto caótico de nuestras respuestas produce la transformación general.

Aunque nos neguemos al cambio, internet es mucho más potente que la imprenta, la radio o la televisión, porque permite una comunicación de tipo transversal y una mejor explotación de la memoria colectiva. Pocas personas han tomado la medida del reto que eso representa. No falta mucho 
tiempo para que a través de un lenguaje inventado el IEML se comprenderá la lengua del otro y se hará comprender la suya, sin estudiar la lengua extranjera. En este año, en el 2010 los internautas deberán tendrán acceso a descargar un software en el sitio del IEML ${ }^{5}$ y utilizarlo. Es el corrimiento definitivo de fronteras lingüísticas entre el Yo y el Tú. La explotación de una inteligencia colectiva y nómada hará que los horizontes de pensamiento se amplíen y esto será un verdadero tributo para la diversidad y la complejidad.

Es necesario conectar esta sociedad del conocimiento con el desarrollo humano. a fin de hacer posible un desarrollo integral que comprenda la economía, la educación, la salud, la seguridad, la transmisión de patrimonios, la investigación o la innovación que han de ser vistos como una organización interdependiente. En el fondo la inteligencia colectiva es la fuente del desarrollo humano.

\section{Despliegue integral de los sujetos complejos como trashumantes}

Reconocerse como trashumantes es saberse un 'sujeto complejo', implica “reconocer” a alguien ‘nuevo’ en nosotros mismos, y más aún, identificarlo, esto es, pensar en dos cosas contradictorias en una misma definición: por una parte admitir que lo que estaba ahí, el ser que recordamos ya no está, y lo que está ahora es un ser que apenas conocemos. Esto implica tener que pensar en el misterio que hay atrapado en nosotros mismos.

Este descubrimiento va de la mano de “aprender a 'contarnos', y a narrarnos; también aprender a contarse de otra manera” (Idem), nos impulsa a la acción, a la creación, a la construcción. La comunidad trashumante nos dota de una identidad narrativa potencialmente compartida por todos, en un contexto social donde prima el silencio, la búsqueda de sentido y la fragmentación de la identidad personal y comunitaria.

Sin duda que el desgarro del horizonte cotidiano se convierte en emergencia de una experiencia migratoria que en la mayoría de los casos se vive en su connotación negativa, con sufrimiento, extrañamiento, nostalgia separación, pérdida material, y escasamente, como experiencia ambulatoria y lúdica. Sin embargo, esta especie de sismo transnacional, de movilidad general tiene un potencial incluyente, en ella estamos todos, como anfitriones y como invitados.

\footnotetext{
${ }^{5}$ Sociólogo y filósofo tunesino Pierre Lévy en la cual expone ideas concisas sobre el desarrollo e implicaciones de la inteligencia colectiva en la sociedad a través de un medio como internet; además comenta a grandes rasgos sobre su actual proyecto de investigación, el IEML (Information Economy Meta Language, una lengua artificial concebida para ser simultáneamente manipulada por los ordenadores y capaz de expresar los matices semánticos y pragmáticos de las lenguas naturales.
} 
Es la misma comunidad que siempre estuvo ahí, que Camina en los pasos de millones de tránsfugas y dislocados que se filtran en las fronteras porosas y recorren los desiertos mares, esos espacios huecos "trans", translocales, trans-modernos, tránsito puro, flujo incesante de hordas ancestrales y trans-actuales, eternas; a contracorriente de los muros que pretenden detener su paso la curiosa quietud del paradigma... 


\section{Bibliografía}

Abufon, A. (2007), Nuevas Miradas, Editorial Universidad Bolivariana, Santiago.

Balandier, G. (1999), El Desorden, La teoría del caos y las ciencias sociales, Gedisa, Barcelona.

Girard, R. (1998), La violencia y lo sagrado, Anagrama, Barcelona.

Kelly, K. (1994), Out of Control: The Rise of Neo-Biological Civilization, Addison-Wesley, Reading. Mass.

Kovadloff, S. (2004), “Caín doliente”, en El otro en la trama intersubjetiva, Leticia Glocer Fiorini, Lugar editorial, Buenos Aires.

Levy, P. (1995), La Inteligencia Colectiva. Por una antropología del ciberespacio, Ediciones la Decouverte, París.

Maffesoli, M. (2004), El nomadismo, vagabundeos iniciáticos, Fondo de Cultura Económica, Barcelona.

Morin, E. (2000), El paradigma perdido. Ensayo de bioantropología, Kairós, Barcelona.

Idem (1984), Ciencia con Conciencia, Anthropos, Barcelona.

Ouaknin, M.-A (1994) Bibliothérapie (Lire, c'est guérir), Seuil, París. 